\title{
Overloading Scenario in Solid State Transformer
}

\author{
Nasiru B. Kadandani ${ }^{* 1,2}$, Mohamed Dahidah ${ }^{1}$ and Salaheddine Ethin ${ }^{1}$
}

\author{
${ }^{1}$ School of Engineering, Newcastle University, Newcastle upon Tyne, NE1 7RU, United Kingdom \\ (E-mail: n.b.kadandani2@ncl.ac.uk, Mohamed.dahidah@ncl.ac.uk, salaheddine.ethni@ncl.ac.uk) \\ 2 Department of Electrical Engineering, Bayero University, PMB 3011, Kano, Nigeria
}

(E-mail: nbkadandani.ele@buk.edu.ng )

\begin{abstract}
Nowadays, solid state transformer (SST) is been considered as an alternative option in smart grid where additional ancillary services that cannot be provided by conventional line frequency transformer (LFT) are required. However, the power transmission capability of SST is limited to that of its semiconductor switches which are power electronics devices. As such SST needs a new way of dealing with overload. This paper presents an investigation into the overloading scenario in SST. The overloading is achieved by modifying the SST control algorithm to include a current limiting controller that modulates the output current as a function of junction temperature.
\end{abstract}

Keywords: Solid state transformer (SST); overload; junction temperature; semiconductor switch operating region.

\section{INTRODUCTION}

Conventional line frequency transformer (LFT) has for long being used in power system for voltage transformation and has proven to sustain overload for a significant amount of time. However, such a transformer is huge and bulky, as such not suitable in applications where space, size, weight, compactness, cable solution, multiport capability and environmental friendliness are critical. Furthermore, when the system gets more complex due to increased integration of distributed generations (DGs) like wind and solar, or during transient disturbances, LFT cannot provide the grid with ancillary services such as harmonic filtering, power factor correction or instantaneous voltage regulation. This drawback therefore call for investigating a new device of achieving both voltage regulation and other ancillary services to the grid.

In this regard, solid state transformer (SST) is the alternative and has already gained the attention of researchers in industries and academia for interfacing renewable energy resources like wind and solar energy with the power grid [1-3]. Other areas where SST have already overtaken LFT include distribution and traction [4-6]. Apart from voltage transformation, SST provides flexible methods for interfacing renewable energy sources with power grid with improved methods of controlling the routing of electricity and power flow, and safe operation of the grid. Other additional features and functions of SST include [7] reduced size and weight, instantaneous voltage regulation, fault isolation, power factor correction, control of active and reactive power flow, fault current management on lowvoltage and high voltage side, active power filtering of harmonic content on the input, good voltage regulating capabilities, possibility of a DC input or output, voltage $\mathrm{dip} / \mathrm{sag}$ ride though capability (with enough energy storage) and smart grid integration.
However, despite all these advantages, SST being a power electronic based transformer, has a very limited overload capability compared to LFT which has proven to sustain overload for a significant amount of time. Therefore, in order to guarantee the reliability of SST in providing the aforesaid ancillary services like emergency power flow control during system disturbances and fast frequency response, an overloading capability is required to be incorporated in the design. In this article, an overloading capability of SST is investigated with a view of exploring its full advantages so that it can effectively compete with LFT in all aspects.

Authors in [8-10] have investigated the possibility of addressing overloading issues in SST by integrating the device with distributed generations (DG) like wind and solar so that during the overload condition, the DG can complement the SST by supplying the additional power to meet the demand. In [8] for example, the SST is supported with solar photovoltaic (PV) and battery energy storage system (BESS) in order to meet the overload demand, while in [9], wind turbine and diesel engine were brought on-board during the overload request to support the SST. An improvement is made in [10] where additional voltage and current controllers were added on the low voltage side of the SST, but still the SST has to be shut down when the current reaches the maximum limit because the junction temperature of the semiconductor switches was not modelled to be part of the control system. This is necessary in order to prevent the SST semiconductor switches from thermal breakdown that can leads to complete failure of the system. These attempts has actually not addressed the overloading scenario in SST as the installation of DGs for example will make the system much more complex and will consequently increase the total cost of the system. In this work, we included junction temperature of the semiconductor switches as an additional constrain on the low voltage side current controller so that the SST can address the overloading issue within itself while ensuring the safety of the semiconductor switches as well.

The remaining part of this article is organized as follows: section II presents a brief overview of SST, section III presents the control method, section IV contains simulation results and discussion, and lastly section $\mathrm{V}$ concluded the article.

\section{OVERVIEW OF SST}

A three stage SST is considered in this research, and it typically consists of three conversion stages, namely; a highvoltage AC-DC power converter that generates a high voltage DC bus, a high-frequency DC-DC converter that produces a regulated low voltage DC bus, and a DC-AC converter that produces a regulated low voltage $\mathrm{AC}$ bus. Thus, the $50 \mathrm{~Hz}$ AC voltage is transformed into a high 
frequency voltage followed by stepping down of the high frequency and finally shaping it back to the desired level at $50 \mathrm{~Hz}$ [11]. A block diagram of a three-stage SST is shown in fig. 1 .

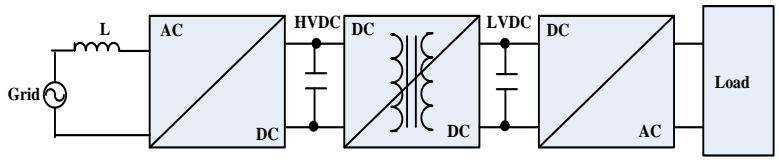

Figure 1: Block Diagram of SST

This configuration has the advantage of having DC link at both low and high voltage sides making it is easier to reject disturbances [12]. Other advantages of this configuration include high flexibility, independent reactive power control, input voltage sag ride through capability, good output voltage and input current regulation, very simple modularity implementation, under and overvoltage protection, voltage sag compensation, renewable energy resources and energy storage integration as well as superior controllability.

\section{a. Input AC-DC Converter}

The input AC-DC converter is responsible for absorbing active power from the HV grid and feeding it to the next stage. The other task for this unit is the control of reactive power for grid services [13]. A full-bridge rectifier is considered here for the task of converting the HVAC input into HVDC because of its simplicity in terms of structure and control, high power quality waveforms, low electromagnetic compatibility (EMC) concerns, high-voltage capability, minimum number of power semiconductors, lower switching losses, and bidirectional power flow.

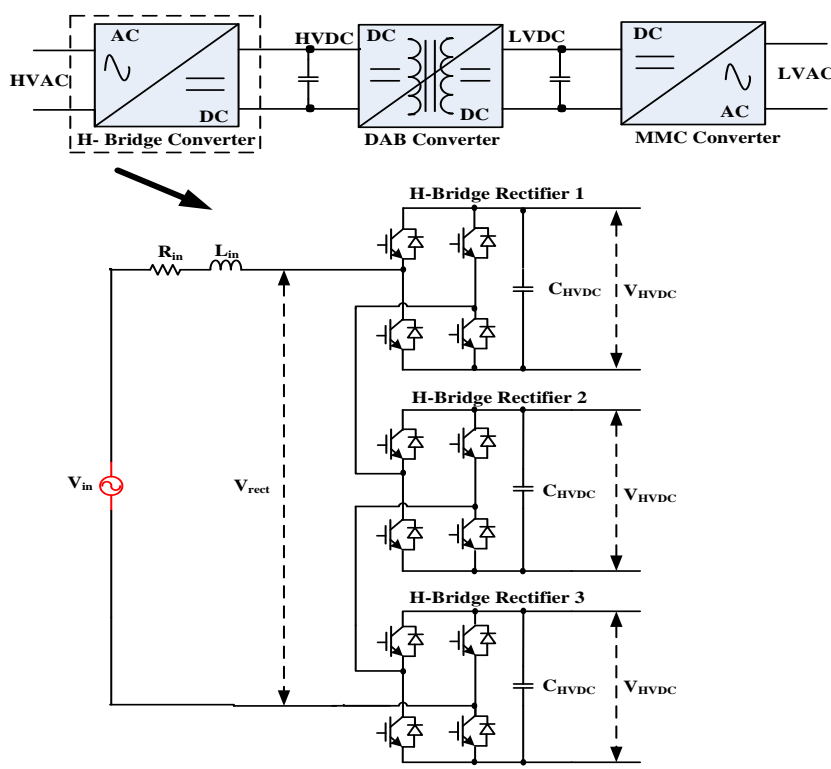

Figure 2: Block Diagram of SST showing Cascaded 3-Module H-bridge Rectifier as an Input AC-DC Converter

\section{b. Isolation DC-DC Converter}

The DC-DC conversion block provides galvanic isolation between the high voltage side and the low voltage side. In this stage, the low frequency high voltage input AC signal of the SST is transformed into low voltage high frequency. This kind of converter is required to have high rated power, high current capability on the low voltage side, high voltage capability on the high voltage side, high frequency isolation and high efficiency [13]. The HVDC link works as a connection point between SSTs and can host new loads, like fast charging electric vehicle stations and distributed resources, large photovoltaic and wind power plants, and battery energy storage systems. The LVDC link offers instead the possibility to connect the DC loads directly to a LVDC grid, avoiding an intermediate conversion stage at the user's site. The DC links allow for the AC power flow separation between the $\mathrm{HV}$ and LV grids. This feature enables controlling the two grids independently, with only the constraint of the active power link.

A Dual Active Bridge (DAB) Converter with high frequency transformer; consisting of a full bridge circuit on both primary and secondary sides is proposed for the task of converting the HVDC to LVDC because of the provision of galvanic isolation, low number of passive components, evenly shared currents in the switches, zero-voltage switching (ZVS) operation in all the switches, soft-switching commutations, automatic bidirectional power flow, high efficiency due to ZVS, wide input voltage range, high stepup ratio, low input current ripple multiport interface capability, power controllability, high power density, buck and boost conversion, high frequency operation, and bidirectional power flow.
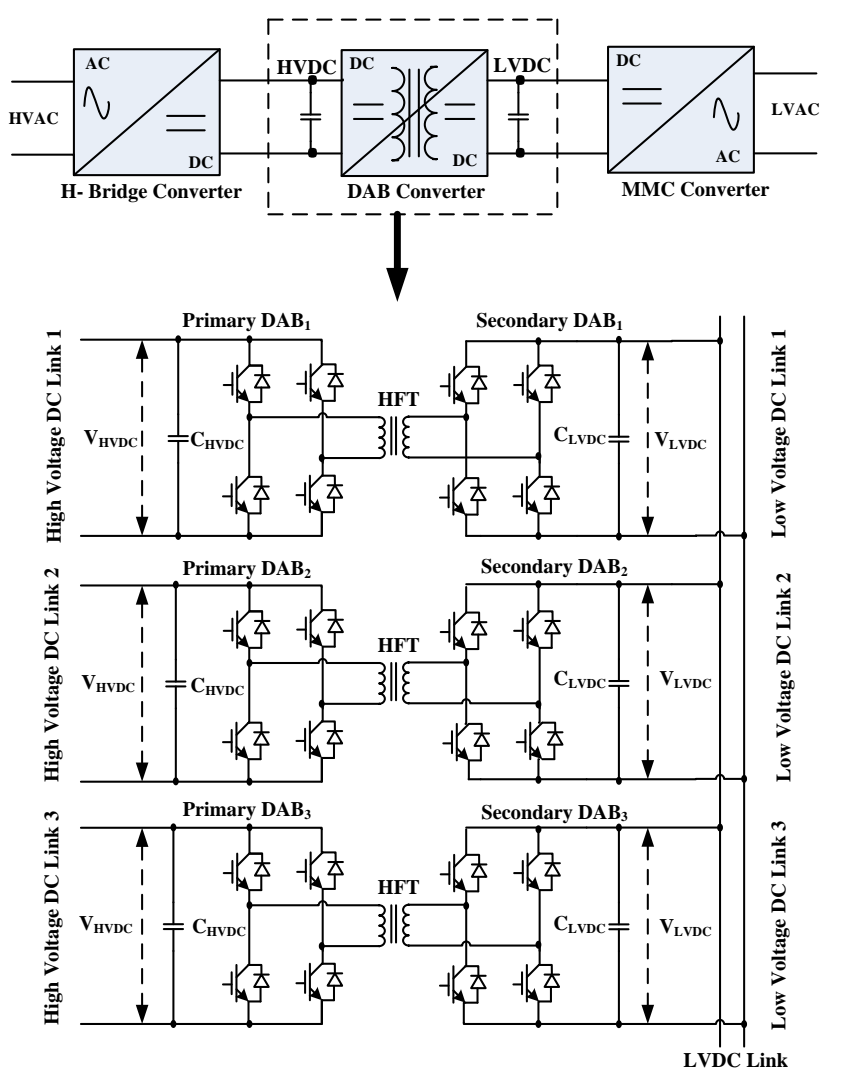

Figure 3: Block Diagram of SST showing Cascaded 3-Module DAB Converter as an Isolation DC-DC Converter

\section{c. Output DC-AC Inverter}

The output DC-DC converter is located on the low voltage side. As such, it has to supply the highest current among the three stages. It is the most exposed to the disturbances on the load side. A modular multilevel converter $(M M C)$ is considered as the candidate inverter because of its modular and flexible nature, low harmonic content, and low switching frequency. 


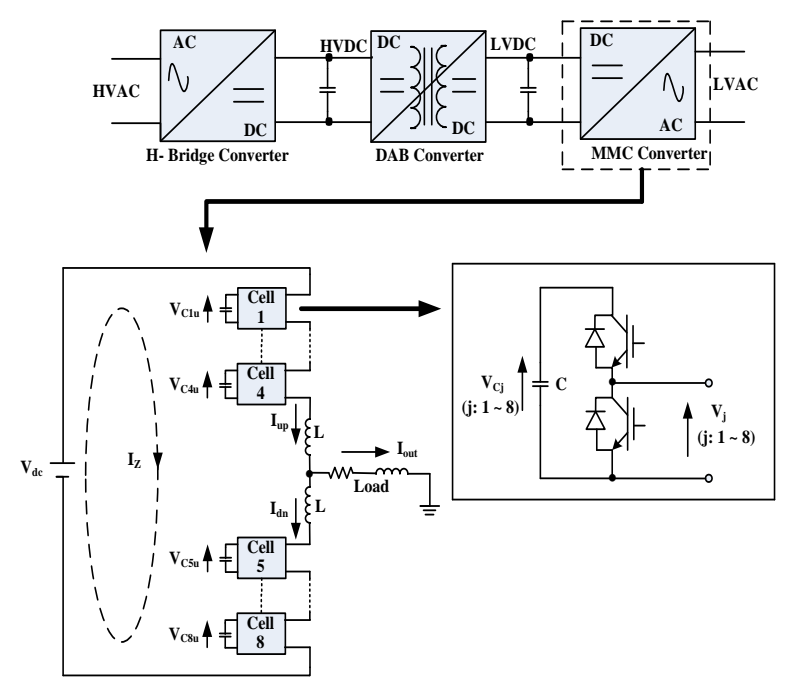

Figure 4: Block Diagram of SST showing Modular Multilevel Converter as the Output DC-AC Converter

\section{CONTROL METHOD}

\section{a. Input Rectifier Control Block}

ADQ synchronous frame controller consisting of an outer voltage loop and two inner current loops is employed for regulating the HVDC link voltage to its reference value, as shown in figure 2. For proper working of the controller, a second phase (imaginary phase) is generated by delaying the original phase by a quarter of a cycle.

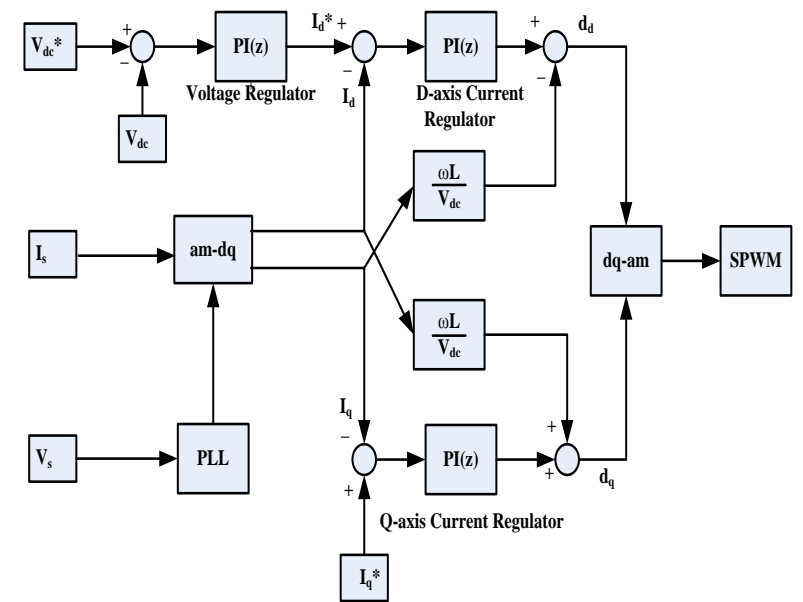

Figure 5: DQ Synchronous Frame Controller for Input AC-DC Converter

\section{b. Isolation DAB Control Block}

A controller is required to ensure equal power transfer between the two converters that form the DAB converter. As such, a power balance controller is developed for ensuring smooth and equal power transfer between the two converters. As shown in fig. 3, this controller is based on adjusting the phase shift between the primary and secondary side $\mathrm{H}$ bridges. In this method, the active component of the rectifier duty cycle is used as the feedback signal for the power balance controller of the DC-DC converter. The power balance is achieved by regulating the phase shift between the primary and secondary H-bridges, and consequently resulting in balancing the voltage at the low DC link side (on the secondary DAB) $[14,15]$

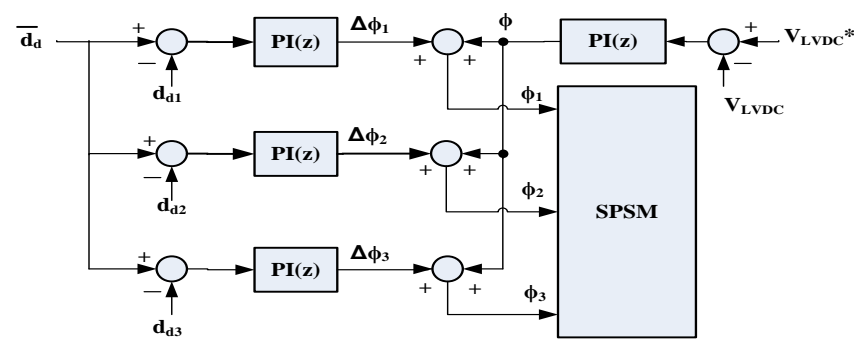

Figure 6: Power Balance Controller for Isolation DC-DC Converter

\section{b. Output Inverter Control Block}

The MMC control algorithm consists of averaging control for regulating the average capacitor voltage; arm balancing control for suppressing any voltage difference between the two arms of the converter and individual capacitor voltage balancing control for regulating the individual voltages in each sub-module [16].

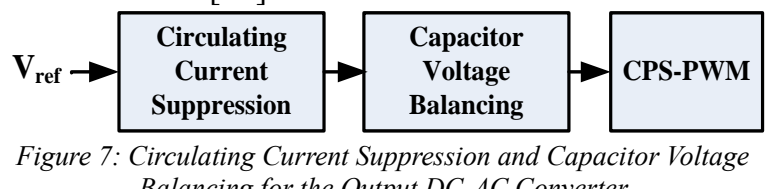
Balancing for the Output DC-AC Converter

\section{c. Overload Control Block}

The overload controller as shown in figure 8 is responsible for extending the operating region of the SST to cater for overload. The proposed controller consists of an electro-thermal model block for loss calculation and junction temperature evaluation; an outer current control (OCC) block for setting the appropriate current limit of the system as a function of junction temperature and a decoupled inner current control (DICC) block for setting the reference voltage for modulation upon Park transformation [17, 18].

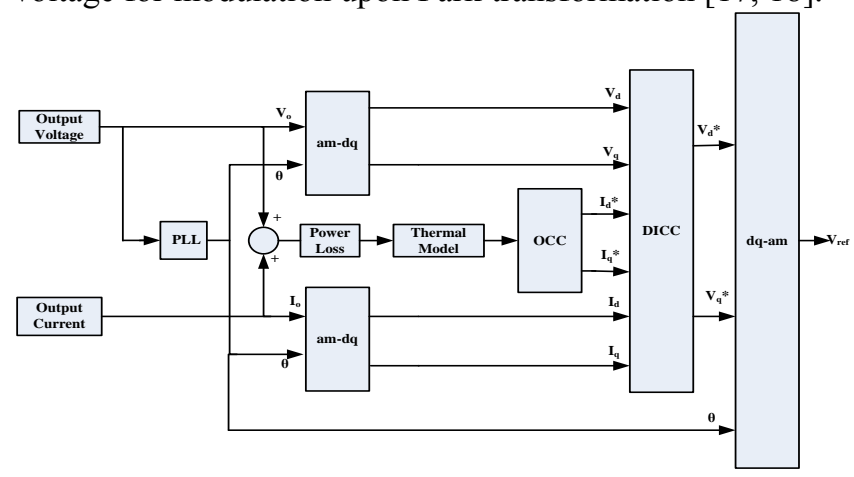

Figure 8: Block Diagram of the proposed SST Overload Controller

The power loss block is made up conduction and switching losses. The conduction losses, $P_{c}$ are as a result of the voltage drop when current flows through the switches while switching losses, $P_{s}$ are related to the simultaneous high voltage and high current experienced by the switches during switching moments.

$$
\begin{aligned}
& P_{C_{-} I G B T}=\frac{1}{T} * \sum_{i=1}^{n}\left[\int_{t_{o}}^{t_{1}} V_{C E}(t) * i(t) d t\right] \\
& P_{C_{-} \text {Diode }}=\frac{1}{T} * \sum_{i=1}^{n}\left[\int_{t_{o}}^{t_{1}} V_{F}(t) * i(t) d t\right] \\
& P_{S_{-} I G B T}=\frac{1}{T} * \sum_{i=1}^{n}\left[i * \frac{E_{\text {on }}+E_{\text {off }}}{I_{C}} * \frac{V_{d c}}{V_{c c}}\right] \\
& P_{S_{-} \text {Diode }}=\frac{1}{T} * \sum_{i=1}^{n}\left[i * \frac{E_{r r}}{I_{c}} * \frac{V_{d c}}{V_{c c}}\right]
\end{aligned}
$$


Where $V_{C E}$ is the collector-emitter voltage of the IGBT, $\mathrm{t}_{\mathrm{o}}$ and $t_{1}$ are the turn on and turn off time of the IGBT and $i(t)$ is the instantaneous current in the system, $E_{\text {on }}+E_{\text {off }}$, is the total on-off energy losses of the IGBT switch, $E_{r r}$ is the diode reverse recovery losses, $I_{c}$ is the maximum collector current, $V_{c c}$ is the maximum collector voltage and $V_{d c}$ is the input DC voltage.

The thermal model is derived from the transient thermal impedance information in the manufacturer's datasheet. The thermal impedance is given by [19].

$Z_{t h}(t)=\sum R_{i}\left(1-e^{\frac{-t}{\tau_{i}}}\right)$

Where $R_{i}$ is the equivalent thermal resistance and $\tau_{i}$ is the thermal time constant for each conduction path. Eqn. (4) can be written in Laplace form as follows:

$Z_{t h}(t)=\frac{R_{1}}{\tau_{1}+1}+\frac{R_{2}}{\tau_{2}+1}+\frac{R_{3}}{\tau_{3}+1}+\frac{R_{4}}{\tau_{4}+1}$

The OCC block sets the allowable current limit for the transformer based on equation 7

$I_{\lim }\left(T_{j}\right)=I_{n o m}+k\left(T_{j(\text { nom })}-T_{j}\right)$

Where $I_{\text {nom }}$ is the nominal current of the system, $T_{j \text { (nom })}$ is the nominal operating junction temperature of the semiconductor switch, and $k$ is the temperature droop constant and it denote the decrease in current limit per unit increase in temperature and is given by [17]:

$k=\frac{I_{\text {nom }}}{T_{j(\max )}-T_{j(\text { nom })}}$

Where $T_{j(\max )}$ is the maximum safe temperature allowed for the semiconductor switch. The value of $T_{j(\max )}, I_{n o m}, I_{c}$, $V_{c c}$ and $E_{o n}+E_{\text {off }}$ used in this study were quoted from the data sheet of FF75R12RT4 Infineon IGBT Module [20].

The DICC block sets the reference voltage for modulation based on Park transformation.

\section{RESULTS AND DISCUSION}

The entire system is simulated in Simulink environment of MATLAB with system parameters shown in table 1.

Table 1: System Parameters for Simulation

\begin{tabular}{|c|c|}
\hline Rating of the SST & $15 \mathrm{kVA}$ \\
\hline \multicolumn{2}{|c|}{ Input AC-DC Converter } \\
\hline AC Source Voltage & $6.6 \mathrm{kV}$ \\
\hline Boost Inductor & $0.32 \mathrm{H}$ \\
\hline HV Side DC Link Voltage & $3.46 \mathrm{kV}$ for each bridge \\
\hline HV Side DC Link Capacitor & $100 \mu \mathrm{F}$ for each bridge \\
\hline Equivalent Switching Frequency & $10 \mathrm{kHz}$ \\
\hline \multicolumn{2}{|c|}{ Isolation DC-DC Converter } \\
\hline LV Side DC Link Voltage & 400V for each bridge \\
\hline LV Side DC Link Capacitor & $1.4 \mathrm{mF}$ for each bridge \\
\hline Transformer Magnetizing Inductance & $28 \mathrm{mH}$ for each bridge \\
\hline Transformer Leakage Inductance & $24.5 \mathrm{mH}$ for each bridge \\
\hline Equivalent Switching Frequency & $10 \mathrm{kHz}$ \\
\hline \multicolumn{2}{|c|}{ Output DC-AC Converter } \\
\hline Number of sub-modules per arm & 4 \\
\hline Sub-Module Capacitance & $4.7 \mathrm{mF}$ \\
\hline Sub-Module Capacitor Voltage & $100 \mathrm{~V}$ \\
\hline Arm Inductance & $3 \mathrm{mH}$ \\
\hline Equivalent Switching Frequency & $10 \mathrm{kHz}$ \\
\hline
\end{tabular}

At the interval $0-5 \mathrm{~s}$ of the simulation time, the SST was operating in normal mode as shown in figure 9 through 18 . Figure 9 shows the high DC link voltage of the SST (at the output of the input AC-DC converter). As expected, the DQsynchronous frame controller was able to regulate this voltage to its reference value. Figure 10 shows the PWM voltage of the input AC-DC rectifier which is seven level as expected. Figure 11 shows the low DC link voltage of the SST (at the output of the DC-DC converter). This voltage was regulated to its reference value by the power balance controller of the DAB converter. Figure 12 shows the primary and secondary currents of the DAB converter while figure 14 shows their corresponding voltages.

At $5 \mathrm{~s}$ of the simulation time, a load step was applied to the output converter of the SST to emulate an overload. It can be seen that the junction temperature (figure 14) of the switches rises and hit a threshold value of $80^{\circ} \mathrm{C}$ at $10 \mathrm{~s}$ which activates the current limiting controller (figure 15). At the interval 5-10s, the SST was able to produce a power of $1.17 \mathrm{pu}$ which represents a temporary overload as shown by the output current and voltage of the SST (figure 15 and 16). The action of the current limiting controller at 10s drops the power level of the SST to $1.1 \mathrm{pu}$. This value is maintained up till 20s when the overload request was withdrawn. As such, the power produced during the interval 10-20s can be regarded as permanent overload because in this interval, both electrical and thermal parameters of the SST are respected. When the overload request was withdrawn, the junction temperature starts to drop down.

Figure 17 and 18 show the sub-module capacitor voltages in the upper and lower arm of the output converter of the SST. This shows that the averaging control, arm balancing control and the individual balancing control maintained the capacitor voltage variation within $2 \mathrm{~V}$ peak to peak before and after the overload; and within $3 \mathrm{~V}$ peak to peak during the overload.
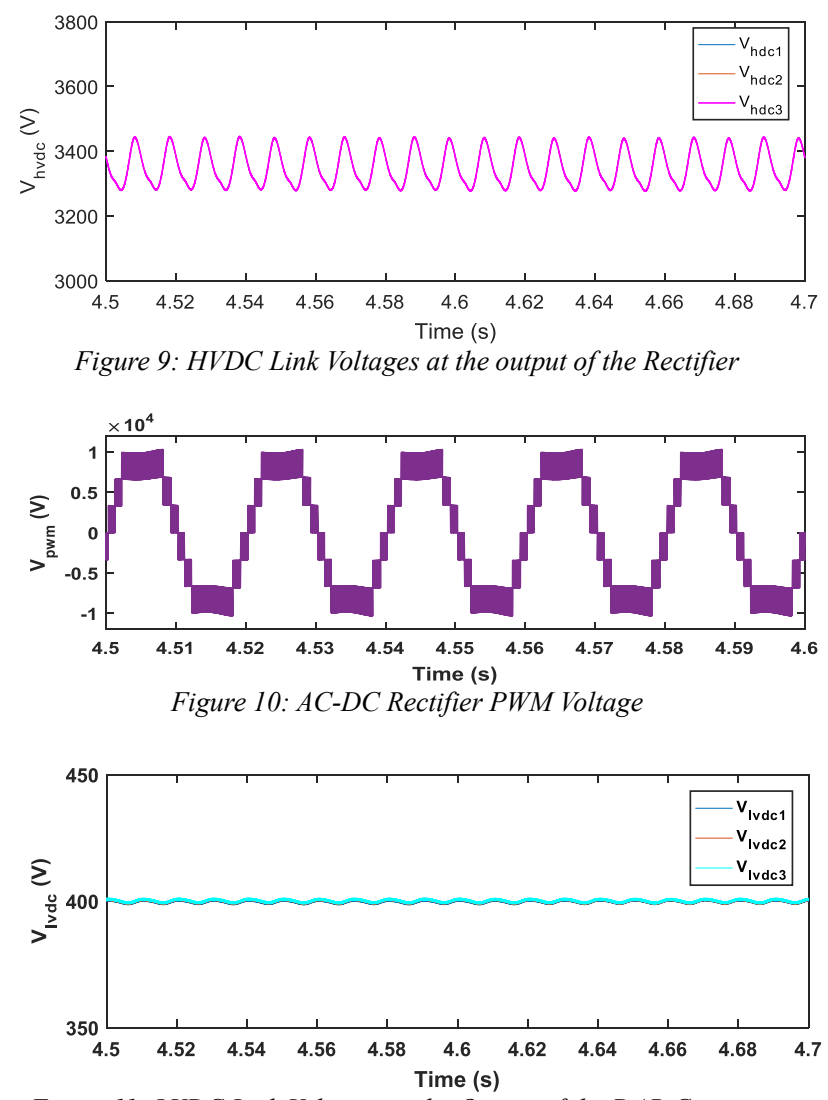

Figure 11: LVDC Link Voltages at the Output of the DAB Converter 

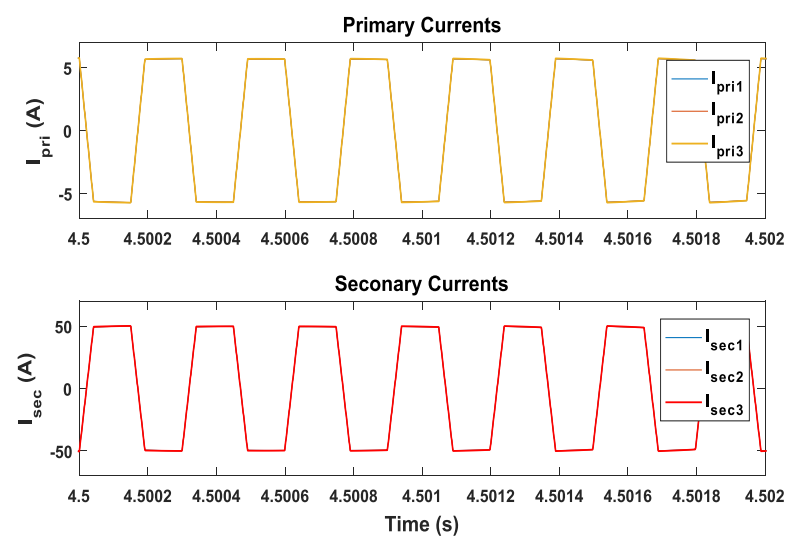

Figure 12: Primary and Secondary Currents of the DAB Converter
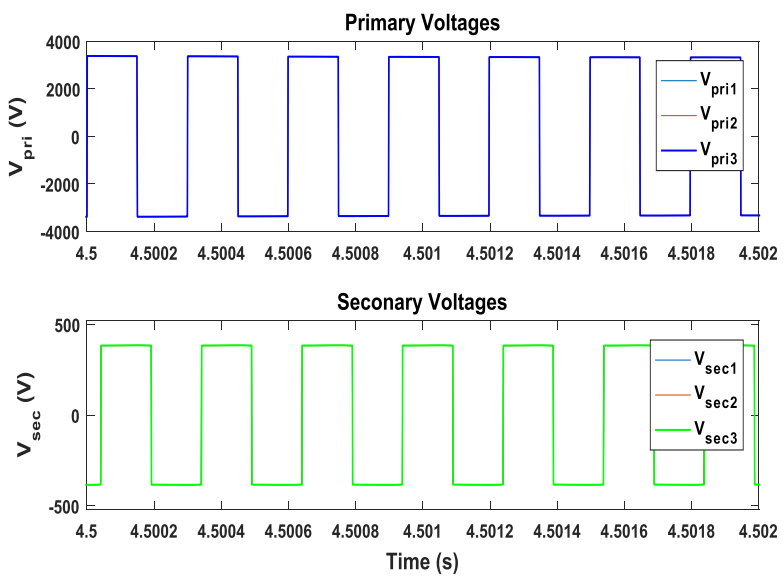

Figure 13: Primary and Secondary Voltages of the DAB Converter

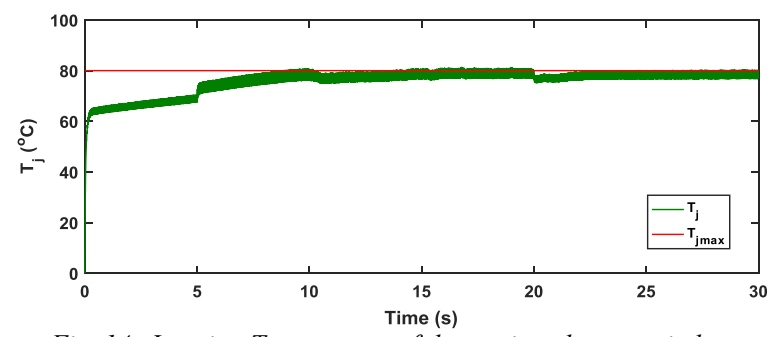

Fig. 14: Junction Temperature of the semiconductor switches

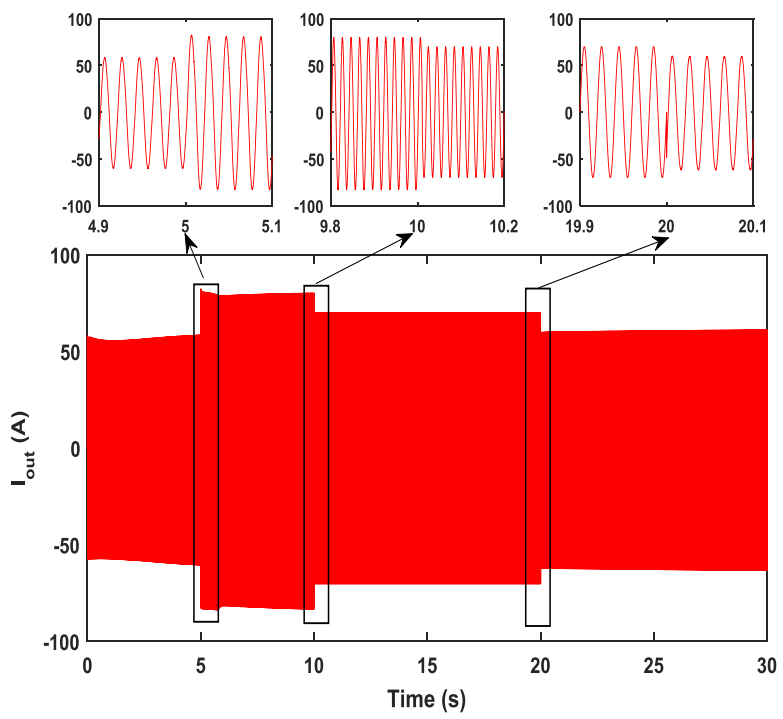

Figure 15 Output Current of the SST

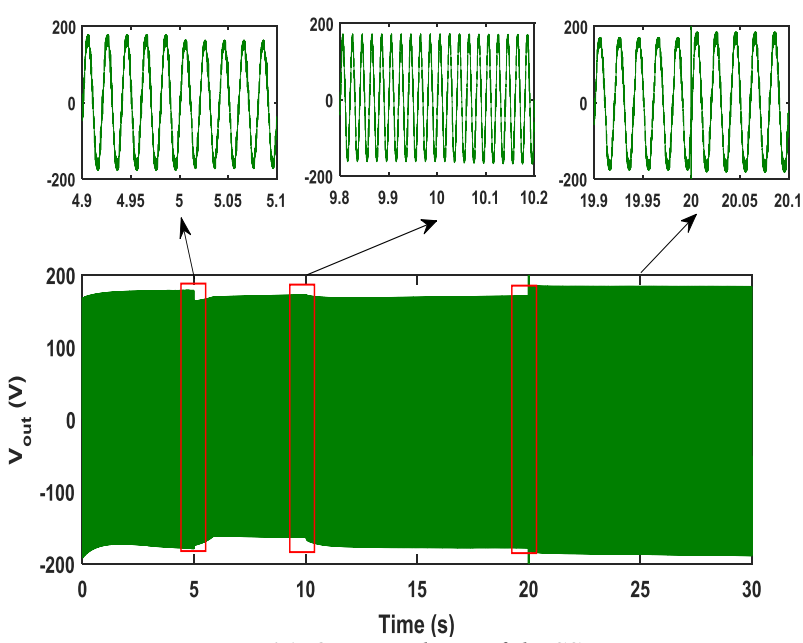

Figure 16. Output Voltage of the SST
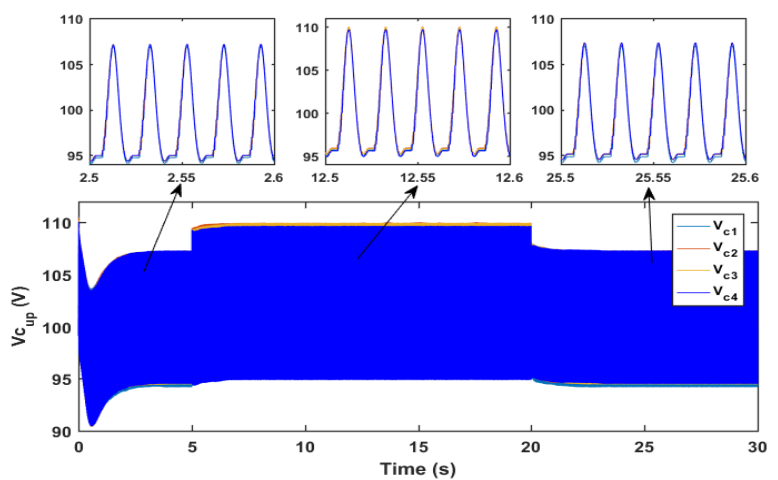

Figure 17: Sub Modules Capacitor Voltages at the Upper Arm of the MMC Inverter
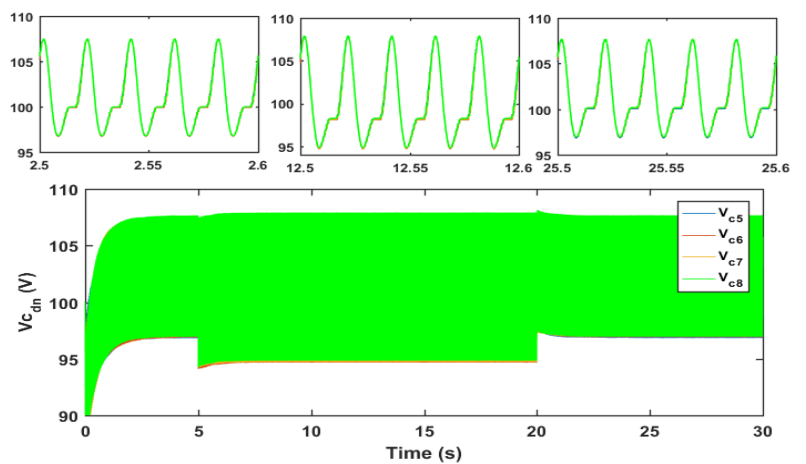

Figure 20: Sub Modules Capacitor Voltages at the Lower Arm of the MMC Inverter

\section{CONCLUSION}

This paper has explored the overloading capability of SST to enable it effectively compete with LFT which has proven to sustain long term overload. A temperature dependent current controller is added to the current control block of the output converter of the device. The additional controller was found to be capable of temporarily extending the operating region of the SST from $1 \mathrm{pu}$ to $1.17 \mathrm{pu}$ and permanent overload of $1.10 \mathrm{pu}$. Simulation results show that the effect of the overloading demand doesn't affect the high voltage side of the SST due to the galvanic isolation between the low and high voltage sides. As such, the SST is proved to be capable of rejecting propagation of disturbances. 


\section{REFERENCES}

[1] R. Gao, X. She, I. Husain, and A. Q. Huang, "Solid-StateTransformer-Interfaced Permanent Magnet Wind Turbine Distributed Generation System with Power Management Functions," IEEE Transactions on Industry Applications, vol. 53 pp. 3849-3861, 2017.

[2] R. Gao, I. Husain, F. Wang, and A. Q. Huang, "Solid-State Transformer Interfaced PMSG Wind Energy Conversion System," Proceedings of IEEE Applied Power Electronics Conference and Exposition (APEC), pp. 1310-1317, 2015.

[3] X. She, F. Wang, R. Burgos, and A. Q. Huang, "Solid State Transformer Interfaced Wind Energy System with Integrated Active Power Transfer, Reactive Power Compensation and Voltage Conversion Functions," Proceedings of IEEE Energy Conversion Congress and Exposition (ECCE), pp. 3140-3147, 2012.

[4] L. Heinemann and G. Mauthge, "The Universal Power Electronics Based Distribution transformer, An Unified Approach," Proceedings of Power Electronics Specialist Conference (PESC), vol. 2, pp. 504-509, 2001.

[5] L.F. Ferreira, G.D. Carne, G. Buticchi, and M. Liserre, "The Smart Transformer - A Solid-State Transformer tailored to Provide Ancillary Services to the Distribution Grid," IEEE Power Electronics Magazine, pp. 56-67 2017.

[6] J. W. Kolar and G. Ortiz, "Solid-State-Transformers: Key Components of Future Traction and Smart Grid Systems " Proceedings of the International Power Electronics Conference - ECCE Asia (IPEC), 2014.

[7] X. She and A. Q. Huang, "Solid State Transformer in the Future Electrical System," Proceedings of IEEE Power and Energy General Meeting (PES), 2013.

[8] G. D. Carne, G. Buticchi, M. Liserre, P. Marinakis, and C. Vournas, "Coordinated Frequency and Voltage Control of Smart Transformers," Proceedings of IEEE PowerTech, Eindhoven, pp. $1-5,2015$.

[9] G. D. Carne, G. Buticchi, M. Liserre, and C. Vournas, "Frequency-Based Overload Control of Smart Transformers," Proceedings of IEEE PowerTech, Eindhoven, 2015.

[10] G. D. Carne, Z. Zou, G. Buticchi, and M. Liserre, "Overload Control in Smart Transformer-Fed Grid," Journal of Applied Sciences, vol. 7, pp. 1-11, 2017.
[11] A. Q. Huang, "Medium Voltage Solid State Transformer, Technology for a Smarter and Resilient Grid," IEEE Industrial Electronics Magazine, pp. 29-42, 2016.

[12] N. B. Kadandani, M. Dahidah, S. Ethni, and J. Yu, "Solid State Transformer: An Overview of Circuit Configurations and Applications," 15th IET International Conference on AC and DC Power Transmission (ACDC 2019), Coventry, UK, pp. 1-6, 2019.

[13] M. Liserre, G. Buticchi, M. Andresen, G. D. Carne, L. F. Costa, and Z. Zou, "The Smart Transformer, - Impact on the Electric Grid and technology Challenges," IEEE Industrial Electronics Magazine, pp. 46-58, 2016.

[14] J. Shi, W. Gou, H. Yuan, T. Zhao, and A. Q. Huang, "Research on Voltage and Power Balance Control for Cascaded Modular Solid-State Transformer," IEEE Transactions on Power Electronics, vol. 26, pp. 1154-1166, 2011.

[15] T. Zhao, G. Wang, S. Bhattacharya, and A. Q. Huang, "Voltage and Power Balance Control for a Cascaded H-Bridge ConverterBased Solid-State Transformer," IEEE Transactions on Power Electronics, vol. 28, pp. 1523-1532, 2013.

[16] M. Hagiwara and H. Akagi, "PWM Control and Experiment of Modular Multilevel Converters," Proceedings of Power Electronics Specialist Conference, pp. 154-161, 2008.

[17] J. Gonçalves, D. J. Rogers, and J. Liang, "Extension of Power Transmission Capacity in MMC-based HVDC Systems through Dynamic Temperature-Dependent Current Limits," Proceedings of 17th European Conference on Power Electronics and Applications (EPE'15 ECCE-Europe), 2015.

[18] N. B. Kadandani, M. Dahidah, and S. Ethni, "On Extending the Overloading Capability of Modular Multilevel Converter," Proceedings of IEEE 13th International Conference on Power Electronics and Drive Systems (PEDS 2019), Toulouse, France, pp. 1-6, 2019.

[19] P. D. Judge and T. C. Green, "Dynamic Thermal Rating of a Modular Multilevel Converter HVDC Link with Overload Capacity," IEEE 2015 PowerTech, Eindhoven, pp. 1-6, 2015.

[20] Infineon, "IGBT Module FF75R12RT4 Data Sheet," 2013. 